\title{
FEIRA DE CIÊNCIAS: \\ Abordando Relações entre Termodinâmica e Corpo Humano
}

\author{
Neiva Mara Puhl ${ }^{1}$ \\ Miriam Ines Marchi²
}

\begin{abstract}
RESUMO
As Feiras de Ciências, bastante populares no Brasil, são vistas como uma oportunidade para que estudantes tanto do Ensino Fundamental quanto do Ensino Médio possam apresentar suas produções científicas. $O$ trabalho tem como objetivo averiguar as potencialidades da Feira de Ciências como um espaço de aprendizagem e suas contribuições para aperfeiçoar a autonomia dos estudantes. Nesse sentido, o estudo é um recorte de uma das atividades desenvolvida com alunos do 20 ano do Ensino Médio de uma escola pública localizada no município de Sinop/MT, durante a intervenção pedagógica de uma aluna do Mestrado Profissional em Ensino de Ciências Exatas. Os estudantes foram avaliados pela pesquisadora levando em consideração, além dos itens exigidos no roteiro, a qualidade do trabalho exposto, a relevância das informações apresentadas sobre o tema, a criatividade, o planejamento e a apresentação de material extra. Também ocorreu avaliação por um grupo de professores convidados pela Comissão Organizadora do evento. A Feira de Ciências possibilitou uma melhor compreensão dos conteúdos abordados durante a intervenção. Além de contribuir para a autonomia dos estudantes na busca de novos conhecimentos, serviu também como um indicativo de que o conhecimento não está pronto e acabado.
\end{abstract}

Palavras-chave: Pesquisa e ensino. Metodologias ativas. Autonomia na busca de conhecimento. Interdisciplinaridade.

\section{SCIENCE FAIR: APPROACHING RELATIONS BETWEEN THERMODYNAMICS AND HUMAN BODIES}

\section{ABSTRACT}

Science Fairs, which are quite popular in Brazil, are seen as an opportunity for students from both elementary and high school to present their scientific productions. The work aims to investigate the potential of the Science Fair as a learning space and its contributions to improve students' autonomy. In this sense, the study is an excerpt from one of the activities, developed with 2nd year high school students from a public school, located in the municipality of Sinop / MT, during the pedagogical intervention of a student of the Professional Master in Teaching of Exact Sciences. The students were evaluated by the researcher taking into account, in addition to the items required in the script, the quality of the work exposed, the relevance of the information presented on the topic, creativity, planning and the presentation of extra material. There was also an evaluation by a group of professors invited by the event's Organizing Committee. The Science Fair provided a better understanding of the content covered during the intervention. In addition to contributing to the students' autonomy in the search for new knowledge, it also served as an indication that the knowledge is not ready and finished.

Keywords: Research and teaching. Active methodologies. Autonomy in the search for knowledg. Interdisciplinarity.

RECEBIDO EM: $16 / 8 / 2019$

ACEITO EM: $7 / 7 / 2020$

\footnotetext{
1 Autora correspondente. Escola Estadual Nilza de Oliveira Pipino. Sinop/MT, Brasil. http://lattes.cnpq.br/0484629493269701. http://orcid. org/0000-0003-1240-6372.neivamarap@gmail.com

2 Universidade do Vale do Taquari - Univates. Lajeado/RS, Brasil. http://lattes.cnpq.br/0309432168792806. http://orcid.org/0000-00032546-7072.
} 
O desenvolvimento de atividades práticas, como Feiras de Ciências, tem se tornado uma metodologia de ensino bastante receptiva e apoiada por professores e comunidade escolar em geral. Embora não se trate de uma metodologia nova, a Feira de Ciências vem sofrendo alterações e adequações conforme exigências da sociedade contemporânea. Os estudantes têm mostrado grande satisfação em participar das atividades, cooperando com trabalhos em grupos e discutindo e defendendo seus pontos de vista a partir de referenciais debatidos e discutidos em sala de aula (MANCUSO; LIMA; BANDEIRA, 1996).

Geralmente as Feiras de Ciências são realizadas nas escolas, após longos trabaIhos baseados no ensino por projetos. Por se tratar de um evento institucional, implica a mobilização da comunidade escolar para a organização do espaço onde ocorrerá o evento. Como qualquer outra atividade de ensino e de aprendizagem, durante os preparativos e no dia da feira há o desenvolvimento de criatividade, autonomia na investigação e busca de soluções para uma situação-problema (BARCELOS; JACOBUCCI; JACOBUCCI, 2010).

A Feira de Ciências não pode ser vista como uma atividade sem propósitos. Deve haver envolvimento e comprometimento tanto de alunos quanto de professores, posto que o evento precisa ser pensado, amplamente discutido e planejado com antecedência, de preferência amarrado aos conteúdos que já vêm sendo abordados em sala de aula. De acordo com Barcelos, Jacobucci e Jacobucci (2010, p. 219), "uma feira científico-cultural requer um pré-projeto, visto que um evento dessa natureza depende de uma série de medidas e providências que devem ser pré-programadas".

A atividade foi desenvolvida com estudantes do 20 ano do Ensino Médio de uma escola pública do município de Sinop/MT, localizado na Região Norte do Mato Grosso. Teve como objetivo averiguar as potencialidades da Feira de Ciências como um espaço de aprendizagem e suas contribuições para aperfeiçoar a autonomia dos estudantes, que foram divididos em 6 grupos e cada grupo ficou responsável em apresentar uma das atividades investigativas da intervenção pedagógica.

Pelo fato de esta atividade compor uma das ações de uma pesquisa de Mestrado, a Feira de Ciências foi realizada no último encontro de intervenção pedagógica, a qual contou com a participação de toda a comunidade escolar. $O$ evento ocorreu ao término da intervenção, na qual foram reapresentadas as principais atividades de investigação feitas em sala de aula e em espaços diferenciados de aprendizagem.

\section{DISCUSSÃO TEÓRICA}

É consenso na comunidade científica que estudantes da Educação Básica apresentam dificuldades de aprendizagem na disciplina de Ciências Exatas. Para promover os processos de ensino e aprendizagem, é importante que o professor experimente várias estratégias de ensino que estimulem a autonomia dos estudantes.

Nesse sentido, uma das metodologias, e bastante popular no Brasil, pode ser a Feira de Ciências, vista como importante aliada na construção e reconstrução de conhecimento, a qual facilita a compreensão de conceitos na área de Ciências. 
No país, as primeiras Feiras de Ciências surgiram na década de 60 do século 20 e se caracterizavam por apresentar trabalhos resultantes de experiências feitas em aula ou criação de aparatos rudimentares com fins demonstrativos (MANCUSO; LIMA; BANDEIRA, 1996). Atualmente esses eventos são abertos à comunidade escolar, oportunizando aos estudantes debates e exposições de pesquisas:

As feiras escolares ocorrem em locais públicos onde os alunos, após uma atividade de investigação científica, expõem e discutem com a comunidade suas descobertas e resultados. É um momento em que os alunos expositores têm a oportunidade de crescimento científico, cultural e social. Essas exposições têm se tornado cada vez mais frequentes nas escolas de educação básica, tanto públicas quanto privadas (PEREIRA; OAIGEN; HENNIG, 2000 apud PUHL, 2018, p. 33).

Comumente emprega-se o termo feira para indicar locais onde se expõem e se vendem mercadorias. Esse termo, entretanto, também é empregado para as Feiras de Ciências escolares. As feiras escolares ocorrem geralmente em locais públicos, onde os alunos, após uma atividade de investigação científica, expõem e discutem com a comunidade suas descobertas e resultados. Os estudantes têm oportunidade de desenvolver seu pensamento e de aflorar o cientista que existe dentro de si, além demonstrar crescimento científico, exercício de autonomia, desenvolvimento cultural e social (PEREIRA; OAIGEN; HENNIG, 2000). Vale destacar que "o local onde a feira se realiza deve ser amplo, bem arejado e confortável, tanto para os expositores quanto para as pessoas que vão prestigiar o evento" (ROSA, 1995, p. 227).

Assim, é importante que a escola valorize atividades como a Feira de Ciências e qualquer outro espaço não formal de aprendizagem. Trabalhar com atividades que priorizem a experiência direta dos estudantes, que contribuem para a sua autonomia na busca de conhecimento, deve ser um compromisso a ser assumido pelas escolas e não só pelos docentes da área de Ciências Exatas. Possibilitar trabalhos no entorno da escola, nos seus jardins, pátios, nos laboratórios escolares, com a construção ou revitalização de espaços adequados a tais atividades, demonstra que a própria escola as valoriza (MANCUSO, 2000, apud STROHSCHOEN; PUHL; MARCHI, 2013, p. 44).

São vários os benefícios oriundos da participação em Feiras de Ciências: crescimento pessoal e ampliação das vivências e conhecimentos; ampliação da capacidade comunicativa; mudanças de hábitos e atitudes; desenvolvimento da criticidade e da capacidade de avaliação; maior envolvimento, motivação e interesse; exercício da criatividade com a apresentação de inovações; politização, principalmente pela formação de lideranças e visão de mundo (MANCUSO, 2000).

Diante dos benefícios oriundos da Feira de Ciências, pode-se inferir que se trata de uma prática pedagógica que favorece a construção e a reconstrução de conhecimento, e ainda auxilia na formação crítica de cidadãos, uma vez que os avanços tecnológicos e as exigências da sociedade contemporânea estabelecem uma reflexão e mudança de postura por parte dos professores para atender essa demanda. Para Barcelos, Jacobucci e Jacobucci (2010, p. 231), esse tipo de atividade "é uma forma de a escola criar oportunidades para os alunos integrarem conteúdos de diferentes disciplinas curriculares, além de abrir espaço para o estudo e trabalho de conteúdos extracurriculares, ocultos no currículo". 
Apesar de trabalhar com metodologias diferenciadas, é importante que ocorra uma revisão e reorganização dos conteúdos, optando por um conjunto de temas que seja relevante para o aluno e abandonando aqueles sem significação. Com essa ação, almeja-se contribuir para a melhoria da qualidade de vida e para a formação de cidadãos críticos com possibilidades de interferir positivamente na comunidade da qual fazem parte (BORGES; LIMA, 2007).

Sobre o assunto, Farias e Terán (2011, p. 54) frisam que, além de modificar os conteúdos, também é indispensável uma mudança de postura por parte do professor no que se refere à metodologia utilizada durante as aulas para atender às demandas da sociedade contemporânea, a qual exige "repensar as estratégias metodológicas visando à superação da aula verbalística, substituindo-a por práticas pedagógicas capazes de auxiliar a formação de um sujeito competente, apto a reconstruir conhecimentos e utilizá-los para qualificar a sua vida".

Nesse sentido, as aulas em espaço não formal podem ser uma estratégia de ensino que possibilita a construção e reconstrução de conhecimento que seja útil e faça sentido para a vida dos estudantes. Conforme Santos (apud STROHSCHOEN; PUHL; MARCHI, 2013, p. 44), o estudante, "[...] ao se inserir na realização da Feira, participa de um processo que resulta na construção de conhecimentos, que muitas vezes não ocorreriam em espaço formal de sala de aula".

Ainda sobre espaços não formais de aprendizagem, Marandino (apud FARIAS; TERÁN, 2011, p. 54) salienta:

Os espaços não-formais envolvem todo e qualquer local que possa ser utilizado para o desenvolvimento de práticas educativas, sejam em parques, bosques, praças, museus, praias entre outros, pois é através destas exposições que se cumprem sua missão educativa. Muitos desses lugares contam com equipes treinadas para auxiliar no direcionamento do público presente.

Vale destacar que é importante que as aulas em espaço não formal sejam bem planejadas e preparadas pelo professor, sendo fundamental elaborar um roteiro com todas as atividades que tem pretensão de realizar. O planejamento deve ser flexível, permitindo que os alunos possam participar ativamente (VIEIRA; BIANCONI; DIAS, 2005).

Em adição, as autoras entendem que é essencial que as aulas não formais ocorram com um bom planejamento prévio, devendo ser estruturadas para alcançar seus objetivos, uma vez que a aula não formal pode até ser mais completa que a aula formal, dependendo da maneira como é ministrada. A participação dos alunos nessas aulas e a forma dinâmica como acontecem, são vistas como positivas pelos professores, pois, na sua concepção, caracterizam-nas como lúdicas e prazerosas, motivando e melhorando a qualidade do ensino de Biologia:

[...] a disciplina de Ciências deveria servir para uma reflexão e posterior investigação do meio que nos cerca, onde o aluno é o agente principal dessa ação. É importante, portanto, que o livro didático não seja a única fonte de informação do professor, já que esse não atende as necessidades atuais de conhecimento (VIEIRA; BIANCONI; DIAS, 2005, p. 23). 
Para Farias e Terán (2011), mesmo diante das dificuldades enfrentadas pelo professor em sala de aula, é importante que ele adote uma postura diferenciada, use de variadas metodologias de ensino, saia de sua zona de conforto e contagie os colegas para participar das aulas em espaços não formais, uma vez que esses espaços são propícios para práticas interdisciplinares:

Apesar das dificuldades, é importante que propostas de educação em espaços não-formais junto às escolas sejam incentivadas e executadas. Tais atividades devem, sempre que possível, envolver o corpo docente. Estes, por sua vez, devem também se preocupar com o local de realização desta prática, procurando um espaço com possibilidades de abordar de forma abrangente todos os aspectos da história, economia, cultura e da natureza com a qual se interage. $O$ ensino em ambientes não-formais deve enfocar a relação entre o ser humano, a natureza e o universo de forma interdisciplinar (FARIAS; TERÁN, 2011, p. 55).

Segundo Pereira, Oaigen e Hennig (2000), o objetivo da realização da Feira de Ciências precisa ser previamente definido e deve apresentar clareza. Dessa forma, ela vai além da formação de pequenos cientistas, abrindo caminhos para práticas interdisciplinares, complementando os conteúdos abordados em sala de aula:

Como estratégia de ensino, as Feiras de Ciências são capazes de fazer com que o aluno, por meio de trabalhos próprios, envolva-se em uma investigação científica, propiciando um conjunto de experiências interdisciplinares, complementando o ensino-formal. Como empreendimento social-científico, as Feiras de Ciências podem proporcionar que os alunos exponham trabalhos por eles realizados à comunidade, possibilitando um intercâmbio de informações (PEREIRA; OAIGEN; HENNIG, 2000, p. 38, grifos dos autores).

Ainda de acordo com esses autores, as Feiras de Ciências têm como objetivos propiciar um conjunto de situações de experiências que possibilitam:

[...] incentivar a atividade científica; favorecer a realização de ações interdisciplinares; estimular o planejamento e execução de projetos; estimular o aluno na busca e elaboração de conclusões a partir de resultados obtidos por experimentação; desenvolver a capacidade do aluno na elaboração de critérios para compreensão de fenômenos ou fatos, pertinentes a qualquer tipo, quer cotidiano, empírico ou científico; proporcionar aos alunos expositores uma experiência significativa no campo sociocientífico de difusão de conhecimentos; integração da escola com a comunidade (p. 20).

Ao participarem da Feira de Ciências os estudantes têm a oportunidade de rever o que foi estudado e explorado durante as atividades de intervenção. Além disso, podem usar sua criatividade para expor das mais variadas formas os conteúdos explanados durante as aulas, sentindo-se responsáveis por seu aprendizado.

\section{METODOLOGIA UTILIZADA}

Este trabalho foi realizado em uma escola pública localizada no município de Sinop/MT. Os envolvidos na pesquisa são alunos de um 2 o ano da referida escola, que possuem entre 15 e 18 anos; alguns residem no centro da cidade e outros na sua periferia. 
A Feira de Ciências interdisciplinar foi pensada e organizada pelas docentes das disciplinas de Biologia e de Ciências com o intuito de propor aos alunos uma atividade de investigação em que eles pudessem expor e discutir suas descobertas com a comunidade escolar. A pesquisa teve abordagem qualitativa.

Este texto é um recorte da pesquisa de uma estudante de um curso de Mestrado Profissional em Ensino de Ciências Exatas. Durante os preparativos da Feira de Ciências estava ocorrendo a intervenção pedagógica dessa mestranda. Assim, as organizadoras do evento lançaram o desafio de participar da feira, juntamente com os alunos, para apresentar as atividades investigativas desenvolvidas com os estudantes durante a intervenção.

Para a efetivação do trabalho foi proposto um grande tema: termodinâmica associada ao corpo humano. Também foi proposta a seguinte problemática de pesquisa para os alunos: "Eis a questão: O corpo humano É ou NÃO É uma máquina térmica"?

Com o tema e a problemática de pesquisa propostos, os estudantes foram divididos em seis grupos. A partir de um sorteio, cada grupo ficou responsável em apresentar uma das atividades investigativas realizadas durante a intervenção pedagógica. Foram apresentadas as seguintes atividades: (1) Comparação do corpo humano ao automóvel; (2) Atividade de campo; (3) Uso do software de simulações PhET; (4) Observação do comportamento alimentar durante 3 dias; (5) Fórmulas e enunciados das Leis da Termodinâmica; e (6) Cálculos energéticos diários para o corpo humano.

Para orientar os alunos durante o planejamento da feira foi produzido um roteiro, no qual constavam informações para a elaboração dos trabalhos a serem desenvolvidos e a respeito da organização da feira. No roteiro fornecido aos estudantes constava que: a apresentação oral do trabalho deveria ser de forma clara, sucinta e não ultrapassar dez minutos; as vestimentas deveriam ser adequadas; o cabelo deveria ser preso; construir, no mínimo, um cartaz explicativo do tema, e os grupos (3) e (6), além da apresentação oral e confecção de cartaz, teriam de usar computador com acesso à internet, balança e trena durante a apresentação.

Os grupos foram orientados a pesquisar sobre as suas atividades e organizar as suas apresentações, mas tiveram autonomia para adotar as estratégias que julgassem mais apropriadas para a exposição do trabalho, desde que seguissem as instruções preestabelecidas no roteiro. A Feira de Ciências foi realizada no mês de agosto de 2017, nos dois turnos escolares (manhã e tarde), em um único dia de evento.

Os trabalhos foram avaliados levando em consideração os itens exigidos no roteiro, a qualidade do trabalho exposto, a apresentação oral, a relevância das informações apresentadas sobre o tema, a criatividade, o planejamento e a apresentação de material extra. Além da avaliação da professora pesquisadora, os trabalhos também foram avaliados por um grupo de professores convidados pela Comissão Organizadora do evento. Todos os avaliadores passaram diante dos trabalhos de cada grupo, e, para não esquecer de nenhum detalhe, fizeram anotações das informações prestadas pelos estudantes. Tais anotações foram utilizadas para analisar os dados da pesquisa. 
O evento foi aberto à comunidade escolar, oportunizando aos alunos envolvidos apresentar e discutir suas atividades de investigação com o público ali presente e entre si.

\section{RESULTADOS E DISCUSSÃO}

A Feira de Ciências foi realizada após as atividades de intervenção. Sendo assim, o evento oportunizou aos estudantes recapitular grande parte das atividades de intervenção feitas em diferentes espaços de aprendizagem, como sala de aula, laboratório de informática e Praça da Bíblia.

Os trabalhos foram expostos na sala de aula, a qual foi organizada com materiais simples, considerando que um dos objetivos da Feira de Ciências era minimizar gastos na sua execução. Dessa forma, a confecção dos cartazes, carrinho e corpo humano foi feita com materiais de baixo custo. É importante que o professor esteja presente guiando e orientando os trabalhos do início até o fim:

Embora os alunos devam ter uma participação ativa na escolha dos seus temas de pesquisa, a orientação do professor é indispensável e insubstituível na hora de apontar possíveis problemas de pesquisa, na indicação da metodologia adequada, na análise dos dados (ROSA, 1995, p. 227).

Como mencionado anteriormente, para a Feira de Ciências foram formados seis grupos, e os temas foram sorteados entre os grupos. Assim, o primeiro grupo (Figura 1) fez uma breve comparação do corpo humano ao automóvel, ponderando sobre os tipos de energia que o carro e o corpo humano necessitam para se locomover e as transformações de energia que ocorrem.

Para explicar os tipos de energia utilizados pelo carro e corpo humano em virtude do seu funcionamento e suas transformações de energia, os estudantes usaram basicamente como aporte a primeira Lei da Termodinâmica $Q=T+\Delta U$. Conforme salientam Halliday, Resnick e Walker (2002, p. 253), acredita-se que a primeira Lei da Termodinâmica pode ser "aplicada a qualquer processo na natureza que se desenvolva entre dois estados de equilíbrio. Não é necessário que todo o estágio do processo seja um estado de equilíbrio, somente os estados iniciais e o final".

Os estudantes explicaram, então, que no carro a quantidade de calorias ingeridas é o combustível e no corpo humano é o alimento. O trabalho que o carro faz são os quilômetros que ele roda, ou quando está parado mas com o motor ligado. A energia interna, no caso do carro, seria o movimento dos pistões, funcionamento do ar condicionado, entre outros. Segundo o entendimento dos alunos, o carro, quando está parado porém com o motor em funcionamento, não gasta energia com a locomoção, mas gasta energia para movimentar os pistões; se o ar condicionado estiver ligado ocorrem gastos de energia com movimento de correia do ar.

Já uma pessoa realiza trabalho quando faz as inúmeras atividades do dia a dia, como andar, estudar, nadar, limpar a casa entre outros. Por outro lado, no corpo humano a energia interna seriam as gorduras armazenadas, a temperatura corpórea, a energia gasta para o funcionamento dos órgãos, entre outros. Pode-se inferir que tais constatações realizadas pelos alunos estão de acordo com o que ensinam Alvarenga e 
Máximo (2013, p. 88): “Quando uma quantidade de calor Q é absorvida (Q positivo), ou cedida ( $Q$ negativo) por um sistema, e um trabalho $T$ é realizado por esse sistema ( $T$ positivo) ou sobre ele (T negativo), a variação da energia interna, $\Delta U$, do sistema é dada por: $\Delta \mathrm{U}=\mathrm{Q}-\mathrm{T}^{\prime \prime}$.

Após as considerações do primeiro grupo, o segundo grupo (Figura 1) ponderou sobre a atividade de campo realizada na Praça da Bíblia, que se localiza nas proximidades da escola e apresenta uma área de 6.042,19 m², a qual é dividida em áreas de lazer, paisagismo e espaço para a prática de atividades físicas. Para apresentar as atividades da Praça os alunos fizeram um cartaz ilustrativo com fotos das atividades físicas executadas, contendo imagens dos estudantes ingerindo e gastando as calorias.

Além disso, trouxeram alguns alimentos para a representação bem como alguns objetos utilizados para efetuar as atividades físicas na praça, os quais ficaram expostos. Para finalizar sua apresentação, expuseram as atividades investigativas realizadas e problematizadas em aula, como a conversão dos alimentos ingeridos em calorias e a conversão das atividades físicas em calorias.

Para uma melhor compreensão do que foi exposto e apresentado, serão exibidas as imagens dos dois grupos realizando suas apresentações no dia da feira.

Figura 1 - Alunos dos grupos 1ํ e 2으 fazendo suas apresentações na Feira de Ciências
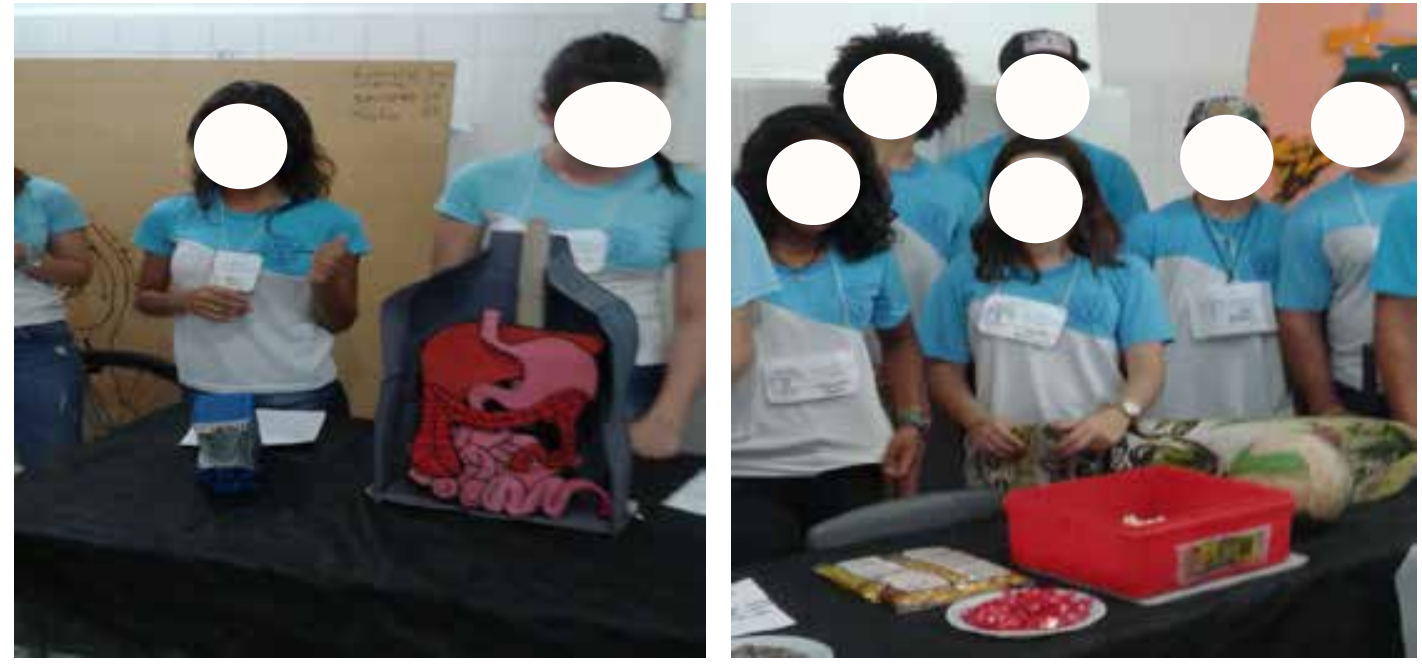

Fonte: As autoras (2017).

Dando continuidade, o terceiro grupo (Figura 2) explicou sobre o uso do software de simulações $P h E T$. Os alunos usaram um computador com acesso à internet, no qual o software PhET foi aberto para todos os visitantes e participantes de Feira de Ciências. Destaca-se que o software em questão dispõe de várias simulações, mas somente uma delas trata das transformações de energia do corpo humano. Sendo assim, para ter acesso a essa simulação os estudantes seguiram os seguintes passos:

- primeiramente escreveram PhET na pesquisa Google;

- em seguida entraram no software e escolheram a disciplina de Física;

- após a escolha da disciplina, escolheram o conteúdo Calor e Termometria;

- dando continuidade, escolheram a simulação Formas de Energia e Transformação;

- por fim, para facilitar o entendimento escolheram o idioma português. 
É importante lembrar que o software possibilita que se vejam as transformações de energia que ocorrem nos sistemas e no nosso corpo e que essas transformações não são vistas sem o uso dessa ferramenta, mas estão sempre ocorrendo no dia a dia e não damos relevância.

O quarto grupo (Figura 2) expôs os resultados da atividade de observação do comportamento alimentar e atividades físicas realizadas em três dias. Essa atividade, que foi explorada durante a intervenção pedagógica, consistia em observar e anotar a quantidade de calorias ingeridas por estudante num período de três dias. Além da ingestão de calorias, os alunos também deveriam observar quantas colorias haviam gasto e, posteriormente, averiguar o saldo energético.

Para facilitar o entendimento dos visitantes e apreciadores da feira, os alunos montaram um cardápio diário de uma pessoa adulta, contendo café da manhã, lanche da manhã, almoço, lanche da tarde, jantar, ceia, outras guloseimas e bebidas. Todos os alimentos contidos no cardápio foram convertidos em calorias. Além disso, expuseram um cartaz contendo as principais atividades físicas que um jovem da idade deles executa diariamente com as possíveis queimas de calorias conforme a atividade realizada.

Seguem as imagens da apresentação do terceiro e quarto grupos.

Figura 2 - Alunos dos grupos 3 e 4 apresentando seus trabalhos na Feira de Ciências
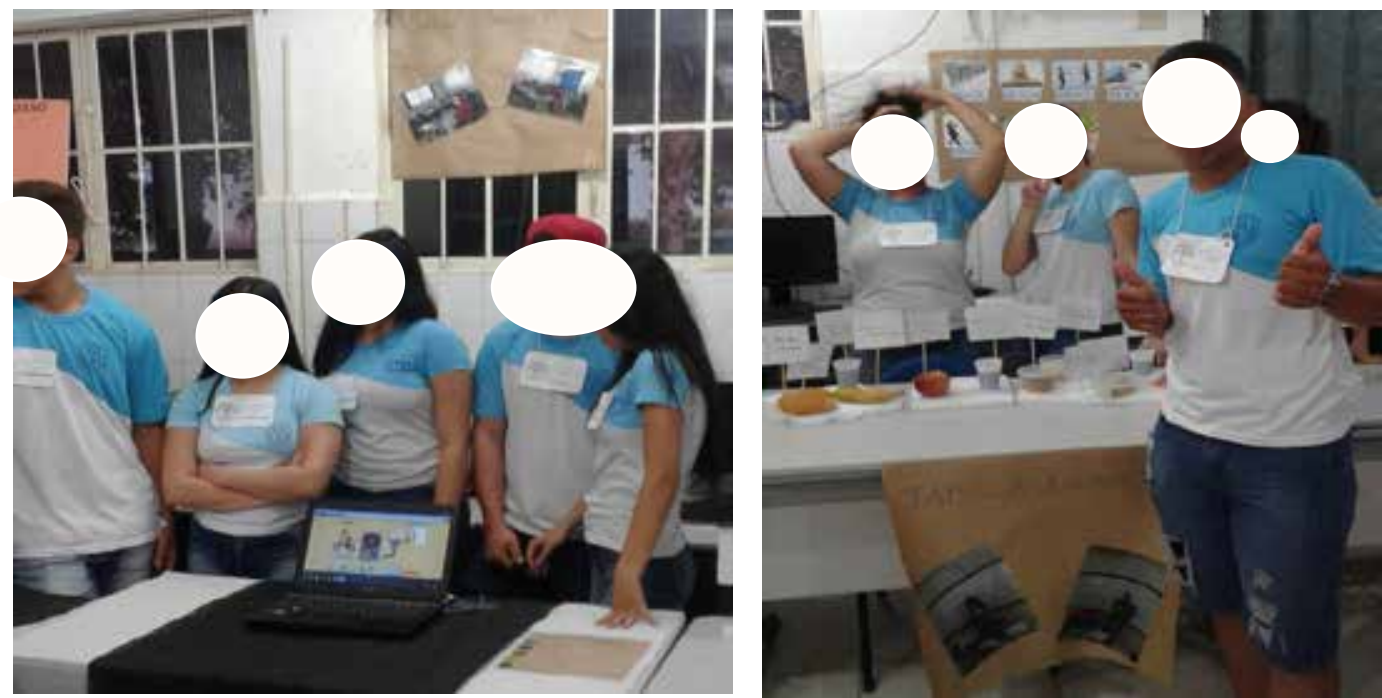

Fonte: As autoras (2017)

A partir dos trabalhos apresentados, percebeu-se que, de fato, "as Feiras de Ciências permitem a divulgação de resultados de pesquisas, trocas de experiências, além de validação dos conhecimentos construídos por alunos e professores" (STROHSCHOEN; PUHL; MARCHI, 2013, p. 47).

O quinto grupo (Figura 3) apresentou as fórmulas e enunciados das Leis da Termodinâmica e expôs alguns dos problemas elaborados e solucionados pelos estudantes no oitavo encontro. Para apresentação, os participantes confeccionaram cartazes contendo as fórmulas e enunciados das Leis da Termodinâmica e deixaram sobre a mesa alguns dos problemas criados pelos estudantes, quando foram usadas as fórmulas expressas nos cartazes. 
O sexto grupo (Figura 3) ficou responsável pelos cálculos energéticos diários para o corpo humano. Em seu espaço de apresentação tinha uma balança para medir a massa dos participantes e visitantes da feira, fita métrica fixada na parede para medir altura e uma calculadora energética que foi encontrada no site https://www.yazio.com/pt/calculadora-calorias-diarias, a qual possibilitou realizar os cálculos de quantas calorias uma pessoa precisa ingerir/dia para manter sua massa atual ou se quiser ganhar ou perder massa.

Seguem as imagens da apresentação do 50 e 6ำ grupos.

Figura 3 - Estudantes do 5ㅇ e 6 ㅇ grupos realizando apresentações na Feira de Ciências
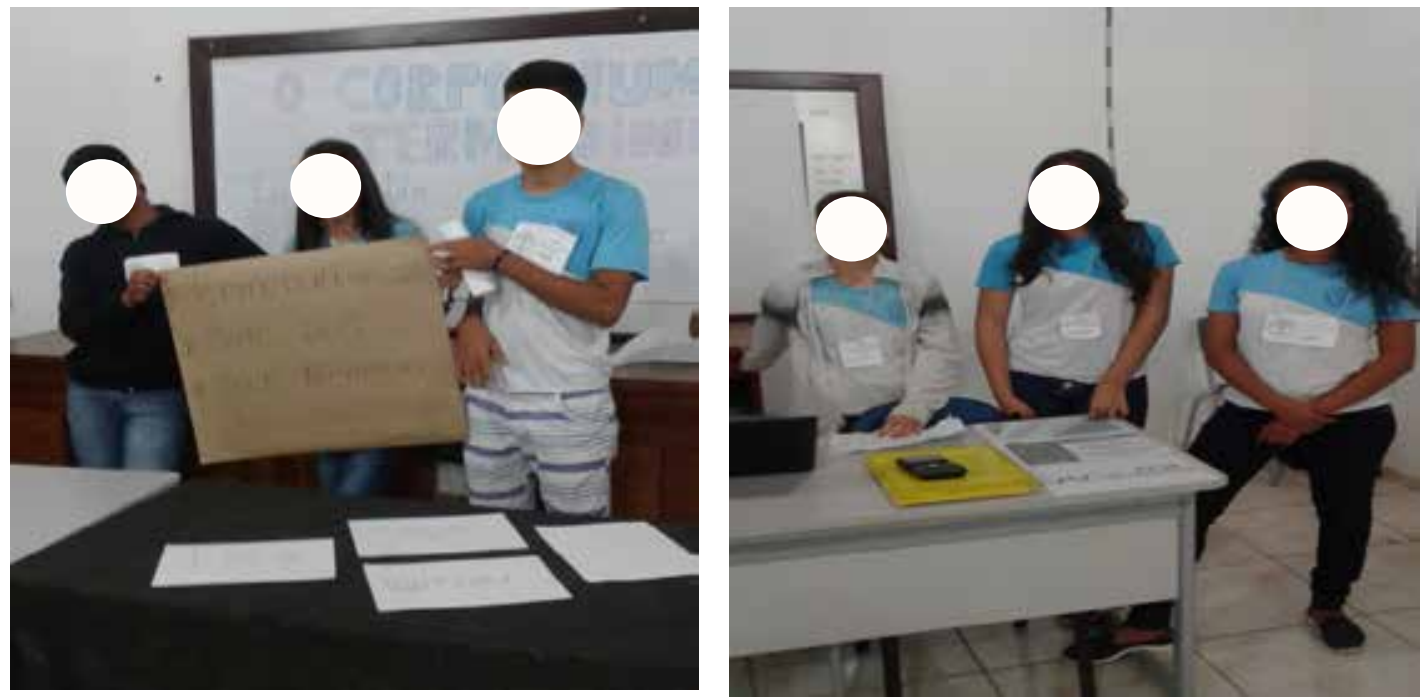

Fonte: As autoras (2017).

Percebeu-se que a interação dos participantes com as atividades realizadas na Feira de Ciências foi muito proveitosa. Os alunos foram elogiados pela inciativa e por levarem informações relevantes à sociedade, que, muitas vezes, faz uso da internet para vários fins menos para produzir conhecimento. Além disso, a atividade possibilitou melhor entendimento dos conceitos da Termodinâmica e crescimento pessoal aos estudantes, que passaram a acreditar no seu potencial, contribuindo, assim, para a autonomia deles.

Conforme salientam Pereira, Oaigen e Hennig (2000), a participação dos estudantes na Feira de Ciências possibilita a divulgação dos trabalhos, a troca de conhecimento e informações entre os alunos da mesma escola e outras escolas, além de novos conhecimentos que são levados para as famílias e comunidade em geral, incentivo ao estudo de Ciências da Natureza e aprofundamento do assunto investigado.

Considerando a Feira de Ciências um espaço não formal de aprendizagem, concorda-se com Vieira, Bianconi e Dias (2005, p. 23) quando afirmam que "nessas aulas, a questão metodológica, a abordagem dos temas e conteúdos científicos apresentados por meio de diferentes recursos e as estratégias e dinâmicas podem contribuir para o aprendizado".

Desse modo, pode-se inferir que, como estratégia de ensino, a Feira de Ciências é uma atividade que ficará na lembrança dos estudantes, e o conhecimento produzido, construído e reconstruído durante sua realização, é útil para a sua vida. Na Feira de 
Ciências praticamente todos os encontros (aulas ministradas durante a intervenção pedagógica) foram relembrados e apresentados para a comunidade escolar pelos próprios estudantes.

\section{CONSIDERAÇÕES FINAIS}

A Feira de Ciências contribui para a autonomia dos estudantes na busca de novos saberes, servindo também como um termômetro, um indicativo de que o conhecimento nunca está pronto e acabado, que ele precisa ser constantemente construído e reconstruído por todos os envolvidos. A forma como os alunos organizaram-se para expor e apresentar seus trabalhos no evento, evidenciou que os estudantes foram além do que foi solicitado, mostrando indícios de autonomia.

Fica evidente que usar diferentes estratégias de ensino, não ficar preso ao livro didático e a aulas em ambiente formal como a sala de aula, fazem toda a diferença e contribuem na construção e reconstrução de conhecimento. Ao utilizar-se ambientes não formais de ensino e de aprendizagem, percebe-se que esses espaços apresentam um grande potencial para uma aprendizagem efetiva, além de possibilitar a interligação entre teoria e prática.

Com a atividade, notou-se maior envolvimento dos alunos, havendo mais interesse, interação e cooperação com os trabalhos que foram apresentados em grupos. Além disso, houve incentivo à pesquisa, trocas de experiências, melhor comunicação, retomada de conteúdos explanados em sala de aula, melhor entendimento sobre os temas estudados, entre outros aspectos.

Para finalizar, a Feira de Ciências pode ser considerada uma atividade que estimula os alunos na busca de conhecimento, além de poder ser vista como uma excelente oportunidade que a escola tem de interagir com a comunidade onde está inserida. Quando bem planejada, é motivadora para alunos e professores, contribuindo para a formação de cidadãos críticos, autônomos e agentes de transformação da sociedade. Ainda, as Feiras de Ciências podem tornar-se atividades prazerosas e com significado quando nelas são trabalhados e apresentados assuntos que fazem parte do cotidiano dos alunos.

\section{REFERÊNCIAS}

ALVARENGA, Beatriz; MÁxIMO, Antônio. Física - contexto e aplicações. 1. ed. São Paulo: Scipione, 2013. BARCELOS, Nora Ney Santos; JACOBUCCI, Giuliano Buzá; JACOBUCCI, Daniela Franco Carvalho. Quando o cotidiano pede espaço na escola, o projeto da Feira de Ciências "Vida em Sociedade" se concretiza. Ciência \& Educação, Bauru, SP, v. 16, n. 1, p. 215-233, 2010. Disponível em: https://www.scielo.br/scielo. php?pid=S1516-73132010000100013\&script=sci_abstract\&tlng=pt. Acesso em: 13 jul. 2018.

BORGES, Regina M. R.; LIMA, Valderez M. R. Tendências contemporâneas do ensino de Biologia no Brasil. Revista Electrónica de Enseñanza de las Ciencias, Porto Alegre, RS, v. 6, n. 1, 2007. Disponível em: http:// reec.uvigo.es/volumenes/volumen6/ ART10_Vol6_N1.pdf. Acesso em: 15 jul. 2018.

FARIAS, Rosa Suzana Batista; TERÁN, Augusto Fachín. Os sons da natureza motivando o ensino da biologia em ambientes não-formais. SaBios - Revista de Saúde e Biologia, Campo Mourão, PR, v. 6, n. 3, 2011. Disponível em: http://revista2.grupointegrado.br/revista/index.php/ sabios2/article/view/892. Acesso em: 17 jul. 2018.

HALLIDAY, David; RESNICK, Robert; WALKER, Jean. Fundamentos de física: gravitação, ondas e termodinâmica. 6. ed. Rio de Janeiro: LTC, 2002. V. 2. 


\section{\& Contexto}

Neiva Mara Puhl - Miriam Ines Marchi

MANCUSO, Ronaldo. Feira de Ciências: produção estudantil, avaliação, consequências. Contexto Educativo - Revista Digital de Educación y Nuevas Tecnologías, Buenos Aires, v. 6, n. 1, p. 1-5, abr. 2000. Disponível em: http://www.redepoc.com/jovensinovadores/ FeirasdeCienciasproducaoestudantil.htm. Acesso em: 10 jul. 2018.

MANCUSO, Ronaldo; LIMA, Valderez Marina do Rosário; BANDEIRA, Vera Alfama. Clubes de Ciências: criação, funcionamento, dinamização. Porto Alegre: SE; Cecirs, 1996.

MARANDINO, Martha. Educação em museus de história natural: possibilidades e desafios de um programa de pesquisa. Revista Electronica de Enseñanza de las Ciências, Porto Alegre, RS, n. extra, VII Congresso, 2005. Disponível em: https://core.ac.uk/download/pdf/13301167.pdf. Acesso em: 12 jul. 2018.

PEREIRA, Antônio Batista; OAIGEN, Edson Roberto; HENNIG, G. Feiras de Ciências. Canoas: Ulbra, 2000.

PUHL, Neiva Mara. Atividades investigativas no estudo da termodinâmica: incentivando a autonomia do estudante. Lajeado/RS. 136f. 2018. Dissertação (Mestrado em Ensino de Ciências Exatas) Univates. Lajeado. 2018.

ROSA, Paulo Ricardo da Silva. Algumas questões relativas a Feiras de Ciências: para que servem e como devem ser organizadas. Caderno Brasileiro de Ensino de Física, Florianópolis, SC, v. 12, n. 3, p. 223-228, 1995. Disponível em: https://periodicos.ufsc.br/index.php/fisica/article/view/7086. Acesso em: 13 jul. 2018.

STROHSCHOEN, Andreia Aparecida Guimarães; PUHL, Claudine Diana; MARCHI, Miriam I. Feiras de Ciências: Formando os Cientistas do Futuro - Ensino Fundamental. Revista Destaques Acadêmicos, Lajeado, RS, v. 5, n. 5, 2013. Disponível em: http://univates.br/revistas/index.php/destaques/article/view/362. Acesso em: 15 jul. 2018.

VIEIRA, Valéria; BIANCONI, M. Lucia; DIAS, Monique. Espaços não-formais de ensino e o currículo de Ciências. Ciência e Cultura, São Paulo, v. 57, n. 4, p. 21-23, 2005. Disponível em: http://cienciaecultura.bvs.br/ scielo.php?script=sci_arttext\&pid=S0009-67252005000400014. Acesso em: 18 jul. 2018. 